Original Article

\title{
FORMULATION DEVELOPMENT AND EVALUATION OF GASTRO-RETENTIVE DOSAGE FORM OF ATAZANAVIR SULPHATE
}

\author{
HEMANT K. JAIN*, MADHURI TAWARE \\ Department of Quality Assurance Techniques, Sinhgad College of Pharmacy, Vadgaon (Bk.), Pune 411041, Maharashtra, India \\ Email: hemantkjain2001@yahoo.co.in
}

Received: 07 Jul 2017 Revised and Accepted: 22 Nov 2017

\section{ABSTRACT}

Objective: To improve dissolution properties of atazanavir sulphate by preparing gastro-retentive granules by solid dispersion method and development of RP-HPLC method for estimation of this drug.

Methods: Estimation of atazanavir sulphate was done using high performance liquid chromatography (HPLC) on inertsil column (5 $\mu \mathrm{m}, 250 \mathrm{x} 4,6$ $\mathrm{mm}$ ) with a mobile phase consists of methanol: water $(91: 9 \mathrm{v} / \mathrm{v})$, at $0.5 \mathrm{ml} / \mathrm{min}$ flow rate and $249 \mathrm{~nm}$ UV detection. The method was validated as per ICH guidelines. Selection of the carrier for gastro-retentive formulation was based on phase solubility study of the drug. Solid dispersions of gastro-retentive granules of different composition of drug and carrier, were prepared by the kneading, heating and solvent evaporation. A $3^{2}$ factorial design was applied to optimize the gastro-retentive formulation. The amounts of polyethylene glycol 6000 (PEG 6000) (X1) and hydroxypropyl methyl cellulose (HPMC) (X2) were selected as independent variables and in vitro-release at 5, $9 \mathrm{~h}$ and total floating time was selected as dependent variables.

Results: HPLC method was found to be linear in a concentration range of $10-60 \mu \mathrm{g} / \mathrm{ml}$ of the drug $\left(\mathrm{r}^{2}=0.999\right)$. The low value of $\%$ RSD in precision study indicates reproducibility of the method. The low value of LOD and LOQ suggests the sensitivity of the method. The solubility enhancement study of drug with various carriers followed descending order of solubility [Gelucire 44/14>PEG 6000>polyvinyl pyrrilidone (PVP)]. Highest \% cumulative release was observed for the heating method at drug polymer (PEG 6000) ratio 1:5. Hence, this ratio has been selected for preparation of solid dispersion. From comparison of dissolution profile of formulated batches, formulation F4 [containing PEG6000 (1.6 g) and HPMC (200 mg)] showed promising dissolution parameters with desired floating properties.

Conclusion: Results obtained by validation studies suggested that the developed HPLC method is simple, accurate, precise and can be used for routine analysis of atazanavir sulphate formulation. Results of evaluation of prepared batches indicate that batch F4 is a promising formulation for gastro-retentive dosage form of drug.

Keywords: Atazanavir sulphate, Formulation development, Gastro-retentive dosage form, Floating granules, RP-HPLC, Validation

(C) 2018 The Authors. Published by Innovare Academic Sciences Pvt Ltd. This is an open access article under the CC BY license (http://creativecommons.org/licenses/by/4.0/) DOI: http://dx.doi.org/10.22159/ijpps.2018v10i1.21179

\section{INTRODUCTION}

Approx. 35 million people were died from acquired immuno deficiency syndrome (AIDS) related illnesses since start of the epidemic and about 36.7 million people were living with human immunodeficiency virus (HIV) infection during December 2015 throughout the world. The number of HIV infected patients is increasing every year [1]. In this context, an effective drug therapy is needed for the treatment of this infection. Atazanavir sulphate is a novel azapeptide HIV protease inhibitor with high specificity which prevents multiplication of HIV [2]. Atazanavir sulphate is chemically (3S,8S,9S,12S)-3,12-bis(1,1-dimethylethyl)-8-hydroxy-4,11-dioxo-9(phenylmethyl)-6-[[4-(2-pyridinyl)phenyl]methyl]-2,5,6,10,13-penta azatetradecanedioic acid dimethyl ester, sulphate (1:1) [3]. Atazanavir sulphate is an antiretroviral drug which belongs to BCS class-2 drugs, associated with poor solubility. Atazanavir sulphate has less bioavailability due to $\mathrm{pH}$-dependent solubility and absorption $[4,5]$.

Therefore, there is need to increase the solubility of this drug. Various techniques are used for solubility enhancement of poorly soluble drugs $[6,7]$. Solid dispersion method has been selected in this project for solubility enhancement by preparing $\mathrm{pH}$ dependent floating granules.

Some methods have been reported for determination of atazanavir sulphate by HPLC [8-12]. In order to reduce the cost of analysis an economical HPLC method has been developed. This paper presents formulation development of gastro-retentive granules of atazanavir sulphate as well as development and validation of RP-HPLC method for estimation of this drug.

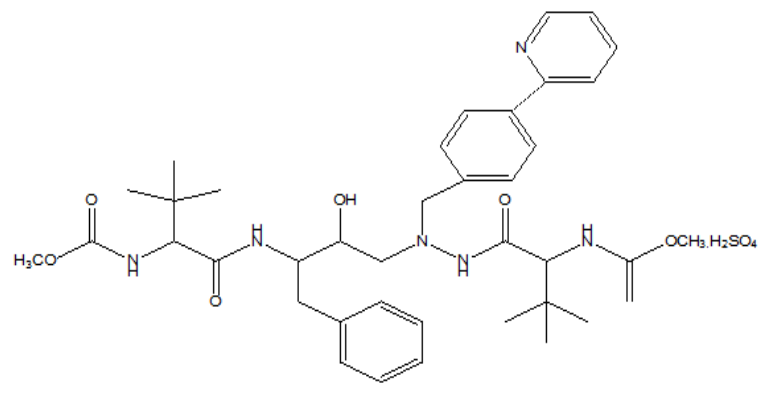

Fig. 1: Chemical structure of atazanavir sulphate 


\section{MATERIALS AND METHODS}

\section{Materials}

Commercially available tablets of atazanavir sulphate (EVOTAZ contain $300 \mathrm{mg}$ ) were procured from local market and atazanavir sulphate API was obtained from an approved supplier. HPLC grade solvents used for analysis were obtained from Loba Chemie Pvt. Ltd., Mumbai, India. Excipients like hydroxy propyl methyl cellulose, polyethylene glycol 6000, gelucire 44/14 were obtained from Analab Fine Chemicals Pvt. Ltd, Mumbai. Polyvinyl pyrrilidone was obtained from Himedia Laboratory Pvt. Ltd. Sodium bicarbonate, magnesium stearate and talc were obtained from Loba Chemie Pvt. Ltd., Mumbai, India.

\section{Instruments}

Shimadzu AY-120 balance and Labindia DS 8000 dissolution test apparatus were used for this work. Analytical method was developed on Inertsil ( $5 \mu \mathrm{m}, 250 \times 4,6 \mathrm{~mm})$ column using Shimadzu LC 2010 CHT quaternary HPLC system with automatic injection facility, LC solution software and UV-Visible detector.

\section{Preparation of standard stock solution}

$100 \mathrm{mg}$ of atazanavir sulphate was weighed accurately and transferred into $100 \mathrm{ml}$ of volumetric flask. About $50 \mathrm{ml}$ of methanol was added to dissolve the content followed by sonication for $10 \mathrm{~min}$. The final volume was adjusted to mark with methanol and mixed well to obtain standard stock solution.

\section{Assay of tablets}

Twenty tablets were weighed and average weight of a tablet was calculated. These tablets were crushed in a glass mortar. An accurately weighed amount of powder equivalent to $100 \mathrm{mg}$ of drug was transferred to a $100 \mathrm{ml}$ of volumetric flask and $30 \mathrm{ml}$ of methanol was added to it. Then the mixture was sonicated for 15 min. and diluted up to mark with the methanol. This solution was filtered through $0.45 \mu$ watman filter paper and further diluted to obtain $60 \mu \mathrm{g} / \mathrm{ml}$ solutions with the same diluent. This procedure was repeated in triplicate. The results of the assay of tablets are shown in table 4.

\section{Validation of the method}

The developed chromatographic method was validated for system suitability, linearity, range, accuracy, precision, LOD, LOQ and robustness parameters as per ICH guidelines.

\section{Linearity and range}

Working standard solutions were injected in the range of 10-60 $\mu \mathrm{g} / \mathrm{ml}$ under optimized chromatographic conditions and peak areas were calculated at $249 \mathrm{~nm}$. A calibration curve was plotted between peak areas against concentrations of the drug. Linear regression data as well as calibration curve were shown in fig. 5 .

\section{Precision}

Repeatability study was carried out with six replicates and intermediate precision studies were carried out with three concentrations of atazanavir sulphate with three replicates. The values of \% relative standard deviation (\% RSD) of precision study are shown in table 5.

\section{Accuracy}

The accuracy of the method was determined by calculating percent recovery of the drug by standard addition method. Percent recovery of atazanavir sulphate was determined at three different level $80 \%$, $100 \%$, and $120 \%$ of the target concentration in triplicate. The results of accuracy study are shown in table 6.

\section{Robustness}

Robustness of the optimized method was studied by changing flow rate $( \pm 0.1 \mathrm{ml} / \mathrm{min})$, change in wavelength $( \pm 1 \mathrm{~nm})$ and change in mobile phase composition $( \pm 1 \%)$ during analysis. The sample was injected in triplicate for every condition and \% RSD was calculated for each condition is shown in table 7.

\section{Limit of detection (LOD) and limit of quantitation (LOQ)}

Five sets of concentrations were prepared between 10-60 $\mu \mathrm{g} / \mathrm{ml}$ and the corresponding areas of these concentration were measured. Calibration curves were plotted for each set. The standard deviation of the y-intercept and average slope of the calibration curve was used to calculate LOD and LOQ using following formulae.

$$
L O D=\frac{3.3 \times S D}{s} L O Q=\frac{10 \times S D}{s}
$$

Where, SD is the standard deviation of y-intercepts of the calibration curves; $\mathrm{S}$ is the mean slope of six calibration curves. [13-15]

\section{Formulation development}

Before formulation, pre-formulation studies (organoleptic properties, solubility and drug excipient compatibility studies) were carried out.

\section{Phase solubility study in different carriers}

In order to determine the most suitable carrier for atazanavir sulphate, phase solubility study was carried out by adding excess of drug $(30 \mathrm{mg})$ in aqueous solution $(25 \mathrm{ml})$ with different carriers like PVP, PEG 6000, gelucire-44/14 at various concentration levels (5\%, $10 \%, 15 \% \mathrm{w} / \mathrm{v})$. The suspensions were continuously stirred on rotary shaker (Remi instruments Ltd) for $24 \mathrm{~h}$ at room temperature. The suspensions were filtered through a $0.45 \mu \mathrm{m}$ Whatman filter paper. The filtrates were suitably diluted and analyzed for the dissolved drug by HPLC.

The Gibbs free energy of transfer $\left(\Delta G^{\circ}{ }^{\circ}\right)$ of drug from pure water to the aqueous solution of carrier was calculated as follows:

$$
\Delta \mathrm{G}^{\circ}{ }_{\mathrm{tr}}=-2,303 \mathrm{RT} \log \frac{\mathrm{S}_{0}}{\mathrm{~S}_{\mathrm{S}}}
$$

Where, $\mathrm{S}_{0} / \mathrm{S}_{\mathrm{S}}$ is the ratio of molar solubility of drug in aqueous solutions of carrier to that of the same medium without carrier. Results are shown in table 8 and fig. 6.

\section{Preparation of solid dispersion}

Solid dispersions were prepared by three different methods and their dissolution profiles were compared with pure atazanavir sulphate.

\section{Melting method}

Three solid-dispersion preparations containing different weight ratios of atazanavir sulphate in PVP, PEG 6000 and gelucire 44/14 $(1: 1,1: 3,1: 5)$ were prepared by the melting method. Atazanavir sulphate was added to the melted PVP, PEG 6000 and gelucire 44/14 at $50{ }^{\circ} \mathrm{C}$ and the resulting homogeneous preparation was rapidly cooled in a freezing mixture of ice and sodium chloride for $1 \mathrm{~h}$. Subsequently, the dispersions were ground in a mortar and sieved through 60\# sieve.

\section{Solvent evaporation method}

Solid dispersions of atazanavir sulphate in containing different weight ratios of PVP, PEG 6000 and gelucire $44 / 14(1: 1,1: 3,1: 5)$ were prepared by the solvent evaporation method. In this method, the drug was dissolved in minimum quantity of methanol and the carriers were added separately to each solution. The resulting mixtures were stirred for $15 \mathrm{~min}$. and evaporated at a temperature of $45-50{ }^{\circ} \mathrm{C}$ on water bath until nearly dry. The evaporated products were ground in a mortar and passed through a sieve 60\#.

\section{Kneading method}

Solid dispersions of atazanavir sulphate in PVP, PEG 6000, gelucire $44 / 14$ in different ratios $(1: 1,1: 3,1: 5 \mathrm{w} / \mathrm{w})$ were prepared by the kneading method. A mixture of PVP, PEG 6000, gelucire 44/14 and Atazanavir sulphate was wetted with water and kneaded thoroughly 
for $30 \mathrm{~min}$ in a glass mortar. The paste formed was dried for $24 \mathrm{~h}$. Dried powder was passed through 60\# sieve.

\section{Evaluation of solid dispersions}

In vitro release of solid dispersions, API and marketed formulation

The release rate of atazanavir sulphate from solid dispersions, API and marketed formulation was determined. The dissolution test was performed using United States Pharmacopeia (USP) type II (paddle) apparatus containing $900 \mathrm{ml}$ of $0.05 \mathrm{M}$ citrate buffer $(\mathrm{pH}-2.8)$ maintained at $37 \pm 0.5^{\circ} \mathrm{C}$ and $75 \mathrm{rpm}$. A sample $(5 \mathrm{ml})$ of the solution was withdrawn from the dissolution apparatus at different time interval viz. 5, 10, 15, 30, 45, 60 min and volume of the sample was replaced with fresh dissolution medium. The samples were filtered through a membrane filter $(0.45-\mu \mathrm{m})$ and diluted to a suitable concentration with $0.05 \mathrm{M}$ citrate buffer. Concentration of these solutions was measured by HPLC. Cumulative percentage drug release was calculated. Results for in vitro release of solid dispersions, API and marketed formulation are presented in table 9, 10 and fig. 7, respectively.

\section{Drug content study of prepared solid dispersions}

About $20 \mathrm{mg}$ of each preparation was placed in a $25 \mathrm{ml}$ volumetric flask. Methanol $(10 \mathrm{ml})$ was added, mixed thoroughly and sonicated for $30 \mathrm{~min}$. The volume was made up to the mark with methanol and then filtered by a Whatman filter paper $(0.45 \mu \mathrm{m}$ pore size $)$. The solution was suitably diluted with the same solvent and the drug content was assayed by HPLC. The percentage drug content was calculated for all batches using following equation:

\section{Drug content $=[$ Drug actual $/$ Drug theoretical $] \times 100$}

Where, drug actual is the actual drug content in $20 \mathrm{mg}$ product and drug theoretical is the theoretical amount of Atazanavir sulphate in 20 mg product. Results of drug content study are shown in table 11 . [15-19]

\section{Formulation of granules}

Floating granules containing atazanavir sulphate were prepared using the melting technique. The drug: carrier ratio (1:5) used to prepare the formulation was selected on the basis of evaluation of solid dispersion. The formulation batches were prepared on the basis of factorial design.

\section{Factorial design}

A $3^{2}$ randomized reduced factorial design was used in this study and 2 factors were evaluated, each at 3 levels; experimental trials were performed at all 9 possible combinations. Quantities of PEG6000 (X1) and HPMC (X2) were selected as independent variables. Percentage release at 5, $9 \mathrm{~h}$ and total floating time were selected as dependent variables. The resulting data were fitted into Stat Ease, Inc. Design Expert 7.0.3 software and analyzed statistically using analysis of variance (ANOVA). The data were also subjected to counter plot methodology to determine the influence of PEG 6000 and HPMC on dependent variables. Total weight of granules of all batches was not constant because that would require the use of diluents for weight adjustment, which in turn may have caused variation in release profile. Thus, we did not alter the amount of diluents in the formulation to nullify any effect due to change in the proportion of diluents. All batches contained $300 \mathrm{mg}$ Atazanavir sulphate, $10 \% \mathrm{w} / \mathrm{w}$ sodium bicarbonate, $2 \% \mathrm{w} / \mathrm{w}$ talc and $2 \% \mathrm{w} / \mathrm{w}$ magnesium stearate. X1 and X2 are the amounts of PEG6000 and HPMC, respectively.

Selected quantity of carrier PEG for each batch was taken as per factorial design and melted at $50{ }^{\circ} \mathrm{C}$; drug was added to it and mixed thoroughly. Sustaining agent HPMC was added separately as per factorial design. These blends were then lubricated with magnesium stearate and talc ( $2 \% \mathrm{w} / \mathrm{w}$ each), mixed well and cooled to room temperature. The mass was passed through a $60 \#$ sieve to obtain the granules.

\section{Evaluation of prepared batches}

Drug content study

Drug content study of prepared batches was similarly performed as procedure of drug content study of prepared solid dispersions.

\section{In vitro buoyancy and total floating time studies}

The in vitro buoyancy was determined by floating lag time. The granules of each batch were placed in a $100 \mathrm{ml}$ beaker containing $0.05 \mathrm{M}$ citrate buffer and the time required for the granules to rise to the surface was determined as floating lag time. The total floating time of granules of each batch were also recorded.

Table 1: Design layout of $3^{2}$ factorial design

\begin{tabular}{|c|c|c|c|c|c|}
\hline & \multirow[t]{2}{*}{ Factors } & \multirow[t]{2}{*}{ Units } & \multicolumn{3}{|c|}{ Levels } \\
\hline & & & -1 & $\mathbf{0}$ & +1 \\
\hline & PEG6000 (X1) & G & 1.6 & 2 & 2.4 \\
\hline & HPMC (X2) & $\mathrm{Mg}$ & 100 & 200 & 300 \\
\hline Response & \multicolumn{5}{|c|}{ Total floating time, $\%$ release at $5 \mathrm{~h}, \%$ release at $9 \mathrm{~h}$} \\
\hline
\end{tabular}

Table 2: Batches designed by using $3^{2}$ factorial design

\begin{tabular}{|c|c|c|c|c|c|c|c|c|c|}
\hline Ingredients & F1 & F2 & F3 & F4 & F5 & F6 & F7 & F8 & F9 \\
\hline Drug (mg) & 300 & 300 & 300 & 300 & 300 & 300 & 300 & 300 & 300 \\
\hline PEG6000 (g) & 1.6 & 2 & 2.4 & 1.6 & 2 & 2.4 & 1.6 & 2 & 2.4 \\
\hline HPMC (mg) & 100 & 100 & 100 & 200 & 200 & 200 & 300 & 300 & 300 \\
\hline Sodium bicarbonate (mg) & 210 & 250 & 290 & 220 & 260 & 310 & 230 & 270 & 320 \\
\hline Magnesium stearate (mg) & 23 & 27 & 31 & 24 & 28 & 32 & 25 & 29 & 33 \\
\hline Talc (mg) & 23 & 27 & 31 & 24 & 28 & 32 & 25 & 29 & 33 \\
\hline Total weight (g) & 2.25 & 2.70 & 3.15 & 2.36 & 2.81 & 3.17 & 2.47 & 2.88 & 3.38 \\
\hline
\end{tabular}

\section{In vitro dissolution studies}

The release rate of atazanavir sulphate from granules was performed under similar conditions as study of release rate from solid dispersions. A sample (5 ml) of the solution was withdrawn from the dissolution apparatus at different time interval viz. 1, 2, 3, $4,5,6,7,8,9 \mathrm{~h}$ and volume of the sample was replaced with fresh dissolution medium. The samples were filtered through a membrane filter $(0.45 \mu \mathrm{m})$ and diluted to a suitable concentration with $0.05 \mathrm{M}$ citrate buffer. Concentration of these solutions was measured by HPLC. Cumulative percentage drug release was calculated. Results of in vitro dissolution studies of atazanavir sulphate are presented in table 12 and fig. 8. [20-23]

\section{RESULTS AND DISCUSSION}

\section{Drug-excipients interaction studies}

Drug-excipients interaction studies were performed using FTIR 
spectrophotometer. The FTIR spectra for the formulation and pure drug are shown in fig. 2 and fig. 3. Characteristics peaks obtained for the pure drug correlated well with that of the formulation peaks. This indicated that the drug was compatible with the formulation components.

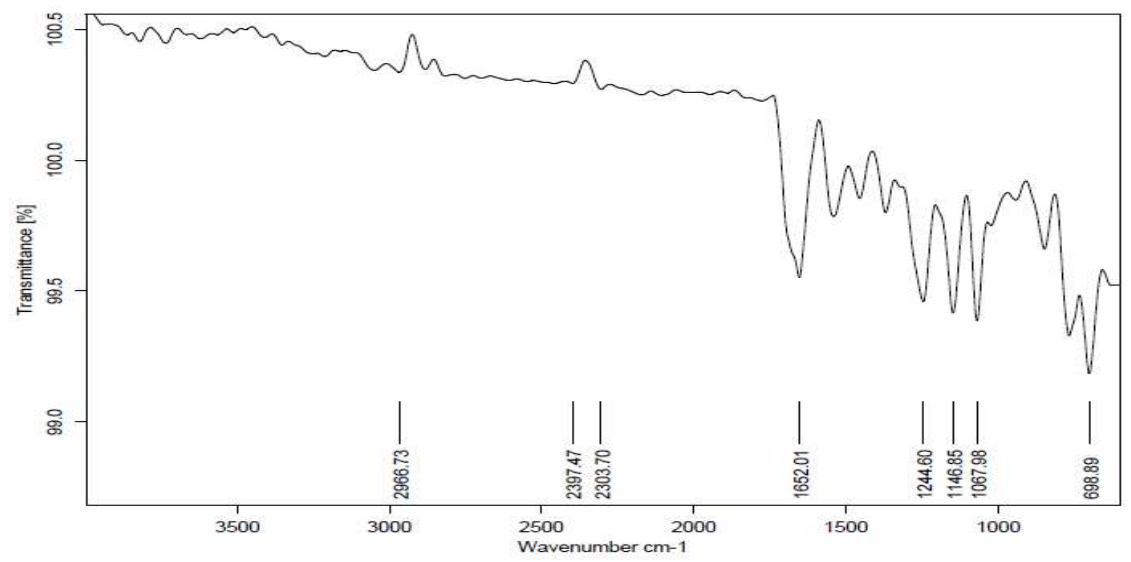

Fig. 2: IR spectrum of atazanavir sulphate

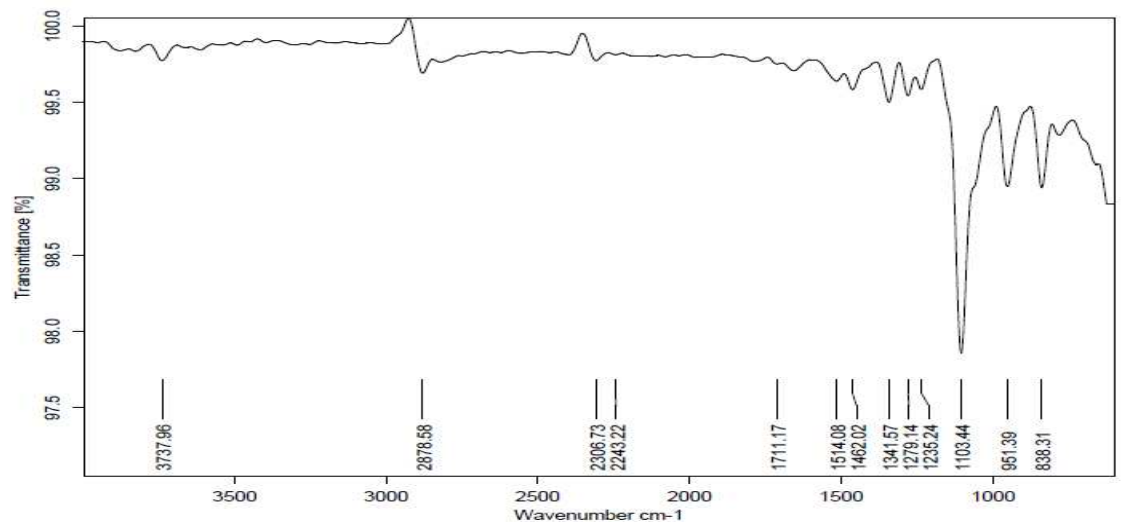

Fig. 3: IR spectrum of atazanavir sulphate formulation

\section{Optimization of chromatographic conditions}

Atazanavir sulphate was found to be soluble in methanol. Therefore, methanol was chosen as diluent. UV spectrum of atazanavir sulphate solution in methanol showed maximum absorbance was found at $249 \mathrm{~nm}$.

Hence, $249 \mathrm{~nm}$ was selected for detection wavelength of this drug. Initially, various chromatographic conditions were tried in order to obtain better separation characteristics by changing mobile phase composition and $\mathrm{pH}$.

Finally, mobile phase methanol: water $(91: 9 \mathrm{v} / \mathrm{v})$ at the flow rate 0.5 $\mathrm{ml} / \mathrm{min}$ was selected with UV detection at $249 \mathrm{~nm}$. The retention time of atazanavir sulphate was found to be $6.61 \mathrm{~min}$.

The chromatogram of atazanavir sulphate is shown in fig. 4 and optimized chromatographic conditions are mentioned in table 3 .

\section{Assay of tablet formulation}

The drug content was calculated as an average of three determinations and assay results were shown in table 4 . The results were close to the labeled value of commercial tablets. The value of mean \% drug was found to be $100.39 \%$, which is within acceptance criteria.

\section{Validation of the method}

The developed chromatographic method was validated for linearity, range, accuracy, precision, LOD-LOQ and robustness parameters as per ICH guidelines.

\section{Linearity and range}

The value of correlation coefficient for atazanavir sulphate (fig. 12) demonstrated the good relationship between peak areas and concentrations. Therefore, the developed method was linear in the concentration range of $10-60 \mu \mathrm{g} / \mathrm{ml}$.

Table 3: Optimized chromatographic conditions

\begin{tabular}{ll}
\hline Parameters & Details \\
\hline Mobile phase & methanol: water $(91: 9 \mathrm{v} / \mathrm{v})$ \\
Column & Inertsil \\
Flow rate & $0.5 \mathrm{ml} / \mathrm{min}$ \\
Detection & $249 \mathrm{~nm}$ \\
Injection volume & $20 \mu \mathrm{l}$ \\
Run time & $9 \mathrm{~min}$ \\
Retention time & $6.61 \mathrm{~min}$ \\
Diluent & methanol: water $(91: 9 \mathrm{v} / \mathrm{v})$ \\
\hline
\end{tabular}


$\mathrm{mV}$

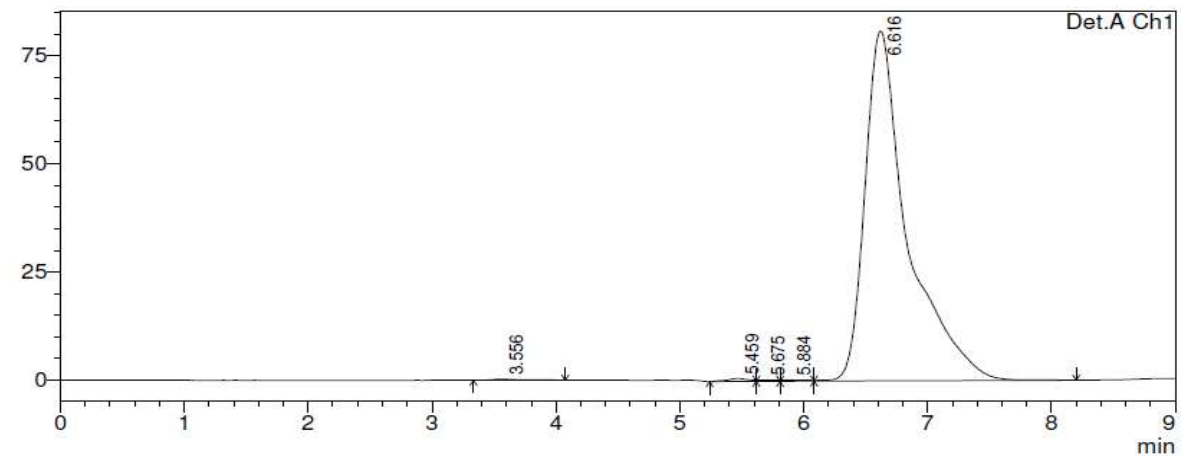

Fig. 4: Chromatogram of atazanavir sulphate

Table 4: Results of assay atazanavir sulphate

\begin{tabular}{lll}
\hline Sample solution concentration $(\boldsymbol{\mu g} / \mathbf{m l})$ & Area & Amount of \% drug estimated \\
\hline 60 & 2631049 & 101.64 \\
60 & 2599849 & 100.43 \\
60 & 2566028 & 99.11 \\
\hline
\end{tabular}

*The value is represented as a mean of 3 observations. Amount of \% drug estimated: Amount of percentage drug estimated, Mean \% drug: Mean percentage drug

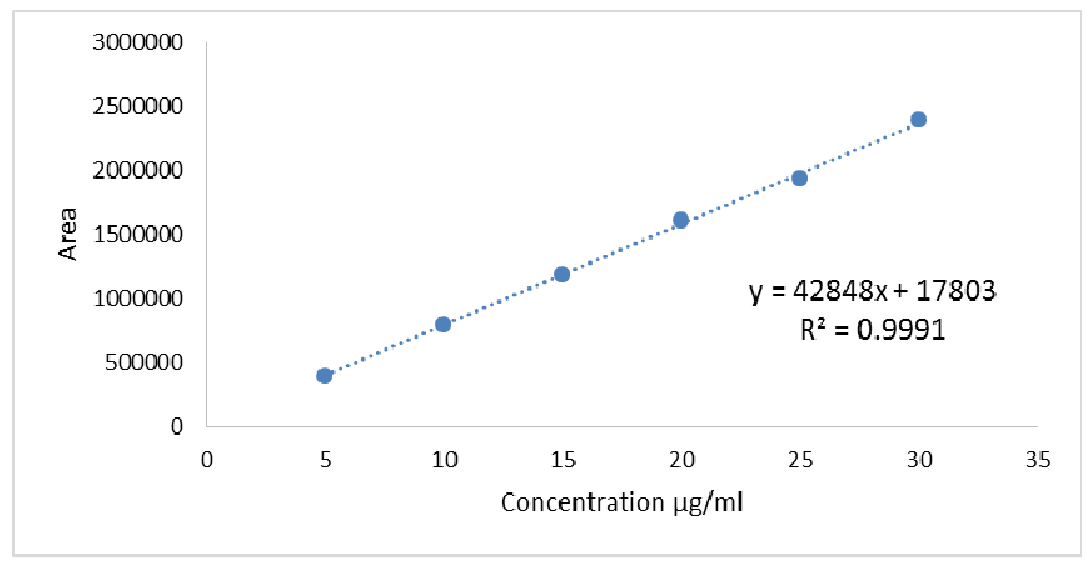

Fig. 5: Calibration curve of atazanavir sulphate in methanol: water $(91: 9 \mathrm{v} / \mathrm{v})$

\section{Precision}

The repeatability, intra-day precision was calculated as the relative standard deviation of results from three samples, during the same day and the inter-day precision was studied by comparing on two different days.

The method is precise and the \% RSD values were within an acceptable limit.

\section{Accuracy}

The value of mean \% recovery and \% RSD at each level was found within acceptance criteria that indicate the method is accurate.

\section{Robustness}

The value of \% RSD in robustness study was found to be within acceptance criteria which showed the reliability of the method.

Table 5: Repeatability and intermediate precision for atazanavir sulphate

\begin{tabular}{|c|c|c|c|}
\hline Precision & Concentration of drug $(\mu \mathrm{g} / \mathrm{ml})$ & Mean area \pm SD* & \% RSD \\
\hline Repeatability* & 60 & $2224683.67 \pm 7029.22$ & 0.31 \\
\hline \multirow[t]{3}{*}{ Intra-day * } & 10 & $482499.66 \pm 8278$ & 1.71 \\
\hline & 30 & $1320427.33 \pm 1414.87$ & 0.107 \\
\hline & 60 & $2749789 \pm 47764$ & 1.73 \\
\hline \multirow[t]{3}{*}{ Inter-day * } & 10 & $421672.55 \pm 4567$ & 1.07 \\
\hline & 30 & $1234366.89 \pm 1680.7$ & 0.13 \\
\hline & 60 & $2561397 \pm 5627.02$ & 0.22 \\
\hline
\end{tabular}

*Each value is represented as a mean \pm SD of $n$ observations. The value of $n$ is 6 for repeatability study and 3 for intraday and inter-day precision. SD: Standard deviation, \%RSD: Percent relative standard deviation 


\section{Limit of detection (LOD) and limit of quantitation (LOQ)}

The sensitivity of measurement of atazanavir sulphate by use of proposed method was estimated in terms of the limit of quantitation (LOQ) and limit of detection (LOD). The values of LOD and LOQ have been found to be $1.16 \mu \mathrm{g} / \mathrm{ml}$ and $3.45 \mu \mathrm{g} / \mathrm{ml}$, respectively. These values show that method is sensitive.

\section{Phase solubility study in carriers}

Direct mixing of drug with carriers produces a direct contact of these components at the solid state leading to high concentration of carrier at the surface of drug which acts as a driving force for the drug to get into solution by reducing the interfacial tension between the drug particles and solubilization solution. Plot of drug solubility against the concentration of carrier indicate a linear relationship of drug solubility in the investigated carrier concentration range. $\Delta \mathrm{G}{ }^{\circ}$ tr values were negative at all levels of carriers shows spontaneity of drug solubilization process. The values shows declining trend with increase in the carrier concentration suggesting that solubilization is more favorable at higher carrier concentration level. The solubility enhancement study of drug with various carriers followed descending order of solubility [Gelucire 44/14>PEG 6000>PVP].

Table 6: Accuracy of atazanavir sulphate

\begin{tabular}{|c|c|c|c|}
\hline Level \% & Amount taken $(\mu \mathrm{g} / \mathrm{ml})$ & \% recovery & Mean \% recovery \\
\hline \multirow[t]{3}{*}{80} & 32 & 102.00 & 101.66 \\
\hline & & 102.00 & \\
\hline & & 100.99 & \\
\hline \multirow[t]{3}{*}{100} & 40 & 100.31 & 105.05 \\
\hline & & 99.99 & \\
\hline & & 99.87 & \\
\hline \multirow[t]{3}{*}{120} & 48 & 96.76 & 99.95 \\
\hline & & 102.11 & \\
\hline & & 100.98 & \\
\hline
\end{tabular}

*Percent recovery was done in triplicate, \% Recovery: Percent recovery, Mean \% recovery: mean percent recovery

Table 7: Robustness study of atazanavir sulphate

\begin{tabular}{lc}
\hline Parameters & \% RSD \\
\hline A: Change in flow rate & $1.46 \%$ \\
$0.9 \mathrm{ml} / \mathrm{min}$ & \\
$1 \mathrm{ml} / \mathrm{min}$ & $1.42 \%$ \\
$1.1 \mathrm{ml} / \mathrm{min}$ & \\
B: Change in Mobile Phase & \\
Methanol: water $(90: 10) \mathrm{v} / \mathrm{v}$ & $1.14 \%$ \\
Methanol: water $(91: 9) \mathrm{v} / \mathrm{v}$ & \\
Methanol: water $(92: 8) \mathrm{v} / \mathrm{v}$ & \\
C: Change in wavelength & \\
$248 \mathrm{~nm}$ & \\
$249 \mathrm{~nm}$ & \\
$250 \mathrm{~nm}$ &
\end{tabular}

*Each value is represented as \% RSD of $\mathrm{n}$ observations. The value of $\mathrm{n}$ is 3 for change in flow rate, change in wavelength and change in mobile phase composition. \%RSD: Percent relative standard deviation

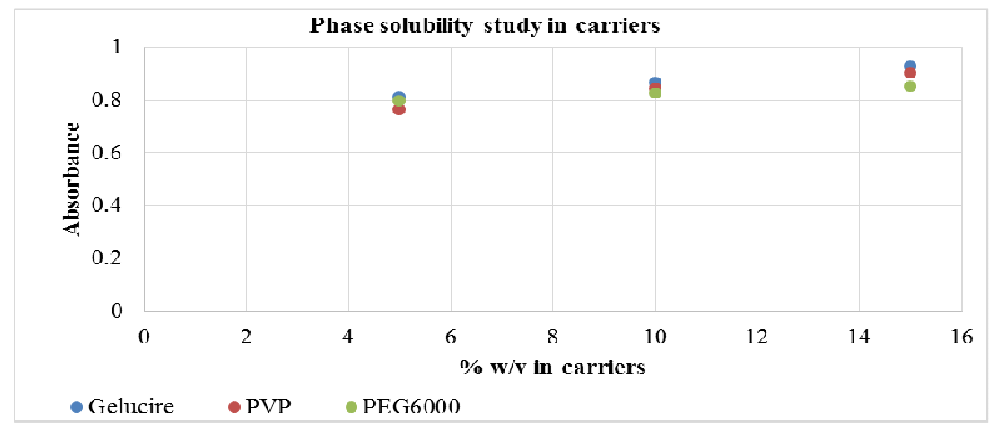

Fig. 6: Phase solubility study incarriers

Table 8: Phase solubility study in carriers

\begin{tabular}{llll}
\hline Carrier & lipid concentration (\% w/v) & Absorbance (mg/ml) & $\Delta \mathbf{G}^{\circ}{ }_{\text {tr }}$ \\
\hline PVP & 5 & 0.051 & -12.11 \\
& 10 & 0.054 & -23.55 \\
PEG 6000 & 15 & 0.055 & -30.85 \\
& 5 & 0.051 & -4.11 \\
Gelucire 44/14 & 10 & 0.057 & -27.23 \\
& 15 & 0.064 & -51.31 \\
& 5 & 0.055 & -19.81 \\
\end{tabular}




\section{Evaluation of solid dispersions}

In vitro release of solid dispersions, API and marketed formulation

Dissolution of prepared solid dispersions carried out in a $0.05 \mathrm{M}$ citrate buffer. From the found data it is evident that dissolution of pure drug is low. \% Cumulative release for API and marketed formulation showed there 66.51 and $85.59 \%$ at $60 \mathrm{~min}$, respectively. Solid dispersions of atazanavir sulphate significantly enhanced the dissolution rate of drug within $60 \mathrm{~min}$. as compared to the drug and marketed preparation.

Highest \% cumulative release (about $98.03 \%$ ) was observed for the heating method at drug polymer (PEG 6000) ratio 1:5. Hence, this ratio has been selected for preparation of solid dispersion.

Table 9: In vitro release of solid dispersions

\begin{tabular}{llll}
\hline Method and ratio & PEG 6000 \% release at 60 min & PVP \% release at 60 min & Gelucire 44/14 \% release at 60 min \\
\hline 1:1 Solvent evaporation & 72.50 & 61.36 & 67.17 \\
1:3 Solvent evaporation & 75.44 & 65.51 & 69.27 \\
1:5 Solvent evaporation & 95.87 & 87.39 & 93.80 \\
1:1 Kneading & 69.62 & 86.33 & 63.40 \\
$1: 3$ Kneading & 74.96 & 62.42 & 65.45 \\
$1: 5$ Kneading & 92.65 & 57.51 & 89.32 \\
1:1 Heating & 77.75 & 64.88 & 68.83 \\
$1: 3$ Heating & 74.46 & 69.74 & 73.25 \\
$1: 5$ Heating & 98.03 & 90.58 & 95.77 \\
\hline
\end{tabular}

Table 10: In vitro release of API, marketed preparation, 1:5 drug: carrier ration PEG 6000 solid dispersion

\begin{tabular}{|c|c|c|c|}
\hline \multirow[t]{2}{*}{ Time (min) } & \multicolumn{3}{|c|}{$\%$ Cumulative release } \\
\hline & API & Marketed preparation & PEG solid dispersion \\
\hline 0 & 0 & 0 & 0 \\
\hline 10 & 18.2 & 31.43 & 51.24 \\
\hline 15 & 24.66 & 47.65 & 66.23 \\
\hline 20 & 32.13 & 60.18 & 73.45 \\
\hline 30 & 49.56 & 73.17 & 80.21 \\
\hline 45 & 55.87 & 79.64 & 90.79 \\
\hline 60 & 66.51 & 85.59 & 98.03 \\
\hline
\end{tabular}

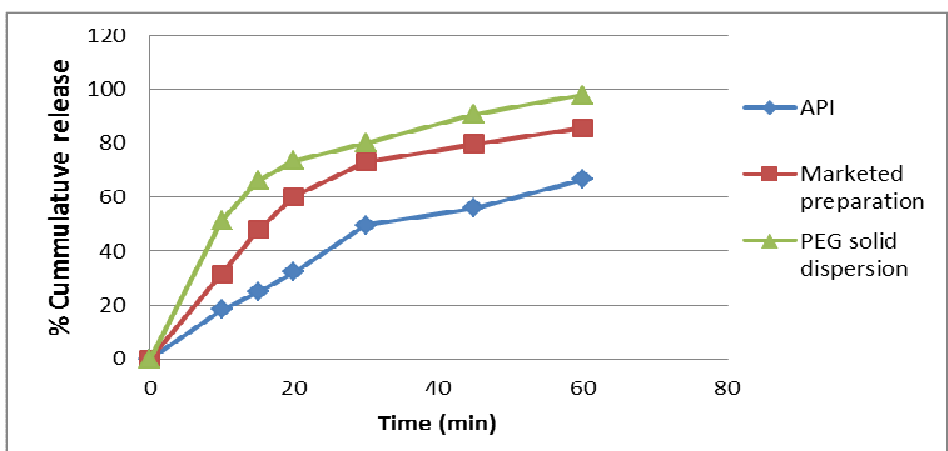

Fig. 7: Comparison of dissolution profile of API, marketed preparation, drug: carrier PEG 6000 (1:5) solid dispersion (n=3 for API, marketed preparation, drug: carrier PEG 6000 (1:5) solid dispersion)

\section{Drug content study of prepared solid dispersions}

Prepared solid dispersion from lipid PEG 6000, PVP, Gelucire 44/14 lipids with three different methods like kneading, solvent evaporation and melting at various concentrations with drug like $1: 1,1: 3,1: 5$ shows majorly drug content in between $94-97 \%$.

\section{Evaluation of floating granules}

Lag time and total floating time was noted visually. The evaluation of prepared floating granules batches showed that batches F1, F2, F4, F5, F7, F8, are having lag time between 30-41 s and total floating time between $20-24 \mathrm{~h}$ and batches F3, F6, F9 having lag time up to $150 \mathrm{~s}$ and total floating time between $15-18 \mathrm{~h}$. This study suggested that as the quantity of PEG6000 and HPMC increased in the formulation, the lag time of granules increased and the total floating time decreased. Optimum quantities of HMPC and PEG6000 were selected in order to produces granules with good gel strength, entrapping carbon dioxide gas, imparting stable and persistent buoyancy.
Once the granules reaches to the surface, they remained buoyant due to which the granules lost their integrity and the size of the swollen matrix reduces because of disintegration and erosion. In fact, the floating time (buoyancy) of the granules is governed by the swelling (hydration) of the hydrocolloid particles on the granules surface when the granules contact the gastric fluids, which in turn results in an increase in the bulk volume.

These factors are essential for the granules to acquire a bulk density of less than 1 and remain buoyant on the gastric fluid. From the findings of the formulation batches, formulation F4 containing PEG6000 (1.6 g) and HPMC (200 mg) showed promising dissolution parameters (\% cumulative release $52.52 \%$ at $5 \mathrm{~h}$ and $99.03 \%$ at $9 \mathrm{~h}$ ) with desired floating properties (minimum lag time and maximum total floating time about $35 \mathrm{~s}$ and $24 \mathrm{~h}$, respectively). From the results, it was clear that the release rate was higher for formulations containing low level of PEG6000 and HPMC compared with other formulations containing higher level. This may be due to release retarding effect of PEG6000 and HPMC at higher concentration because drug may have entrapped 
within carrier matrix causing a decrease in the rate of drug release. Therefore, required release rate of drug can be obtained by adjusting the composition of PEG6000 and HPMC.

From comparison of dissolution profile of formulated batches, batch F4 is considered as optimized formulation.

\section{Factorial design}

Results from ANOVA (Response Surface Linear model) for cumulative \% release of $5,9 \mathrm{~h}$ and total floating time are given in table $13,14,15$ respectively and their respective counter plots are given in fig. 9, 10, 11, respectively.

Table 11: Drug content study of prepared solid dispersions

\begin{tabular}{llll}
\hline Method and ratio & PEG 6000 \% drug yield & PVP \% drug yield & Gelucire 44/14 \% drug yield \\
\hline 1:1 Solvent evaporation & 95 & 96 & 96 \\
1:3 Solvent evaporation & 95 & 97 & 97 \\
1:5 Solvent evaporation & 95 & 90 & 96 \\
1:1 Kneading & 96 & 90 & 90 \\
1:3 Kneading & 95 & 94 & 94 \\
1:5 Kneading & 94 & 89 & 94 \\
1:1 Melting & 97 & 95 & 95 \\
1:3 Melting & 96 & 94 & 89 \\
1:5 Melting & 96 & 96 & 97 \\
\hline
\end{tabular}

Table 12: Evaluation of floating granules: Formulation and dissolution characteristics of batches in a $3^{2}$ factorial design

\begin{tabular}{|c|c|c|c|c|c|}
\hline Batch & Lag time (s) & Total floating time(h) & $\%$ release at $5 \mathrm{~h}$ & $\%$ release at $9 \mathrm{~h}$ & $\%$ Drug content \\
\hline F 1 & 30 & 23 & 60.95 & 84.40 & 95 \\
\hline F 2 & 36 & 21 & 42.56 & 80.13 & 95 \\
\hline F 3 & 120 & 18 & 35.36 & 72.49 & 95 \\
\hline F 4 & 35 & 24 & 52.52 & 99.85 & 98 \\
\hline F 5 & 40 & 21 & 37.76 & 77.90 & 95 \\
\hline F 6 & 132 & 17 & 33.30 & 69.53 & 94 \\
\hline F 7 & 37 & 24 & 50.02 & 95.14 & 97 \\
\hline F 8 & 41 & 20 & 35.44 & 72.85 & 96 \\
\hline F 9 & 150 & 15 & 27.99 & 65.09 & 96 \\
\hline
\end{tabular}

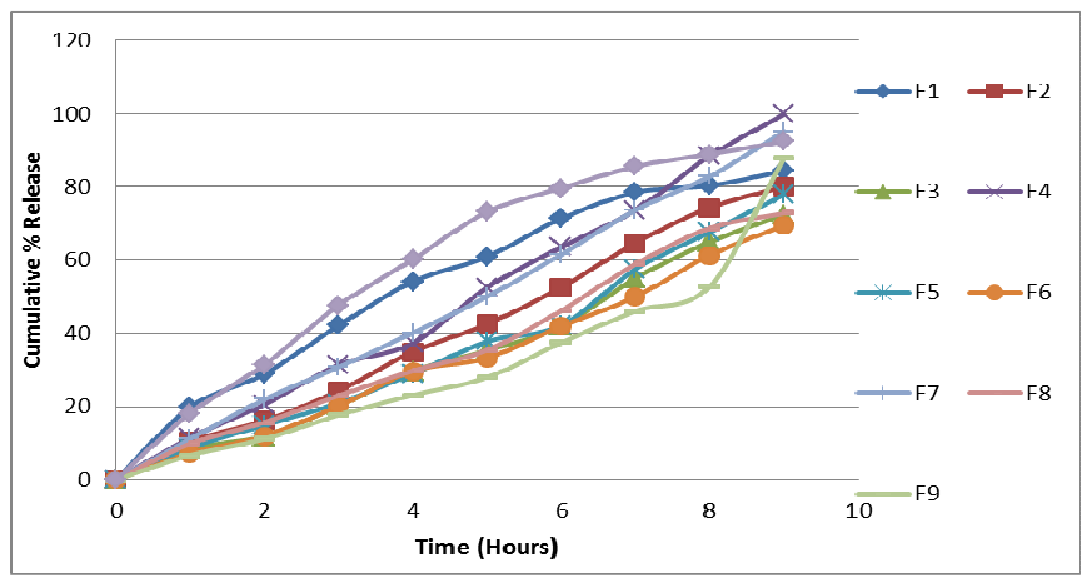

Fig. 8: Graphical representation of In vitro dissolution profile of formulations $(n=3)$

Formulation optimization has been done by using $3^{2}$ factorial design to determine the effect of amount of PEG6000 (X1) and HPMC (X2) on independent variables like total floating time, \% release at 5 and 9 h. Here counter plots are presented to show the effect $\mathrm{X} 1$ and $\mathrm{X} 2$ on dependent variables. The computer generated counter plots for the effect of factorial variables are shown in fig $10,11,12$, respectively. The data demonstrate that both $\mathrm{X} 1$ and $\mathrm{X} 2$ affect the drug release and floating time. As the amount of carrier in the formulation increases the dug release rate decreases. Hence, it can be concluded that drug release and total floating time may be changed by appropriate selection of $\mathrm{X} 1$ and $\mathrm{X} 2$ levels. ${ }^{* * \mathrm{P}}$-values $<0.05$ for total floating time, $\%$ release at 5 and $9 \mathrm{~h} 0.0003,0.0069,0.0001$, respectively. Hence the ANOVA indicate that regression models were significant and valid for each considered response, proving that this factorial design model is significant.

Table 13: Analysis of variance-response for $\%$ release at $5 \mathrm{~h}$

\begin{tabular}{llllll}
\hline Source & Sum of squares & Df & Mean square & F value & p-value Prob>F \\
\hline Model & 852.29 & 2 & 426.15 & 43.56 & 0.0003 \\
A-PEG 6000 & 107.70 & 1 & 107.70 & 11.01 & 0.0160 \\
B-HPMC & 744.60 & 1 & 744.60 & 76.12 & 0.0001 \\
Residual & 58.69 & 6 & 9.78 & & \\
Cor Total & 910.99 & 8 & & & \\
\hline
\end{tabular}




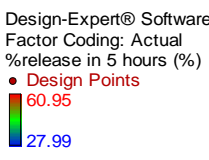

$X 1=A: P E G 6000$ $X 2=B \cdot H P M C$

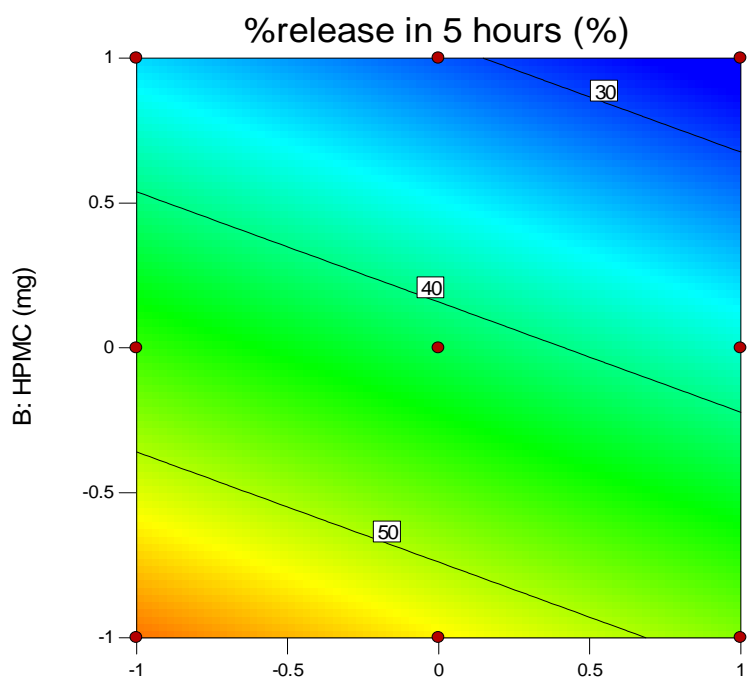

A: PEG 6000 (gm)

Fig. 9: Counter plot for cumulative \% release at $5 \mathrm{~h}$ of formulations as function of PEG 6000 and HPMC

Table 14: Analysis of variance table-Response for $\%$ release at $9 \mathrm{~h}$

\begin{tabular}{llllll}
\hline Source & Sum of squares & Df & Mean square & F value & p-value Prob>F \\
\hline Model & 884.56 & 2 & 442.28 & 12.73 & 0.0069 \\
A-PEG 6000 & 1.98 & 1 & 1.98 & 0.057 & 0.8191 \\
B-HPMC & 882.58 & 1 & 882.58 & 25.40 & 0.0024 \\
Residual & 208.44 & 6 & 34.74 & & \\
Cor Total & 1093.01 & 8 & & & \\
\hline
\end{tabular}

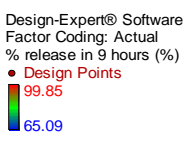

$X 1=A: P E G G 000$
$X 2=B: H P M C$

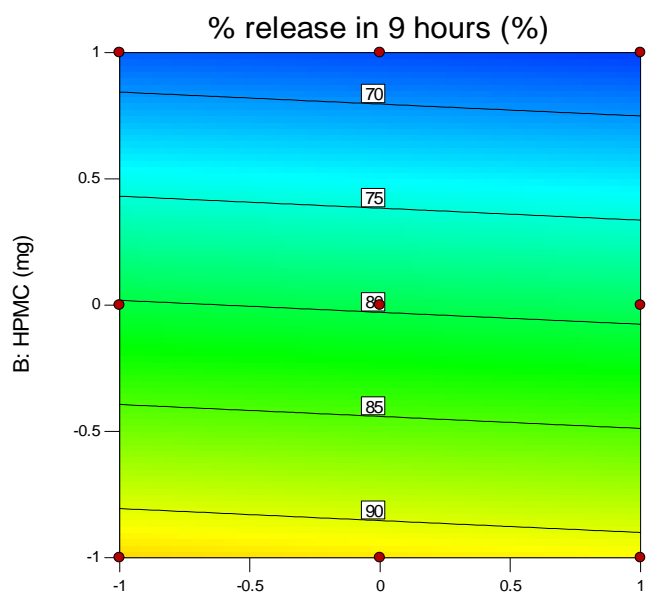

A: PEG $6000(\mathrm{gm})$

Fig. 10: Counter plot for cumulative \% release at $9 \mathrm{~h}$ of formulations as function of PEG 6000 and HPMC

Table 15: Analysis of variance table-response for total floating time

\begin{tabular}{llllll}
\hline Source & sum of squares & Df & Mean square & F value & $\begin{array}{c}\text { p-value } \\
\text { Prob>F }\end{array}$ \\
\hline Model & 79.00 & 3 & 26.33 & 131.67 & $<0.0001$ \\
A-PEG 6000 & 1.50 & 1 & 1.50 & 7.50 & 0.0409 \\
B-HPMC & 73.50 & 1 & 73.50 & 367.50 & $<0.0001$ \\
Residual & 1.00 & 5 & 0.20 & & \\
Cor Total & 80.00 & 8 & & & \\
\hline
\end{tabular}

*Values of "Prob>F" less than 0.0500 indicate above model terms are significant 


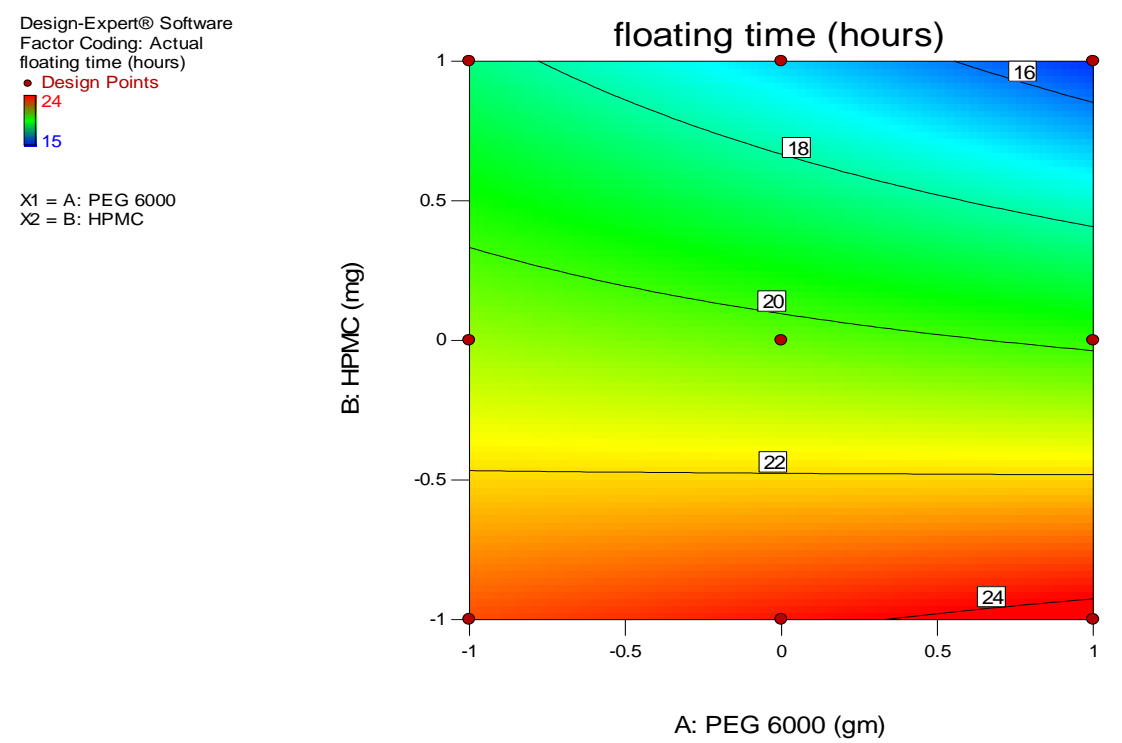

Fig. 11: Counter plot for total floating time of formulations as function of PEG 6000 and HPMC

\section{CONCLUSION}

Results obtained by validation studies suggested that the developed HPLC method is simple, accurate, precise can be used for routine analysis of atazanavir sulphate formulation. Selection of the carrier for gastro-retentive formulation was based on phase solubility study of the drug. Significant dissolution of drug was observed for solid dispersion by heating method at 1:5 ratio of drug and carrier PEG 6000. Gastro-retentive granules of atazanavir sulphate were developed by $3^{2}$ factorial design. Results of evaluation of prepared batches indicate that batch $\mathrm{F} 4$ is a promising formulation for gastroretentive dosage form of drug.

\section{ACKNOWLEDGEMENT}

Authors are grateful to Principal, Sinhgad College of Pharmacy, Pune for providing required facility to complete this project.

\section{AUTHOR CONTRIBUTIONS}

Both authors contributed equally to this work

\section{CONFLICT OF INTERESTS}

\section{Declared none}

\section{REFERENCES}

1. UNAIDS report on the global AIDS epidemic; 2016. Available from: www.unaids.org/globalreport/default.htm. [Last accessed on 05 Jun 2017]

2. Goldsmith D, Perry C. Atazanavir. Drugs 2003;16:1679-93.

3. Raja A, Lebbos J, Kirkpatrick P. Atazanavir sulphate nature reviews. News Anal 2003;2:857-8.

4. Kis O, Walmsley S, Bendayan R. In vitro and in situ evaluation of $\mathrm{pH}$-dependence of atazanavir intestinal permeability and interactions with acid-reducing agents. Springer Sci Business Media New York 2014;31:2404-19.

5. Saxena A, Padmanabhan S, Gautam S, Chowan G, Desikan S. Prediction of $\mathrm{pH}$ dependent absorption using in vitro, in silico and in vivo rat models: early liability assessment during lead optimization. Eur J Pharm Sci 2015;76:173-80.

6. Kalepu S, Nekkanti V. Insoluble drug delivery strategies: review of recent advances and business prospects. Acta Pharm Sin B 2015;5:442-5.

7. Savjani K, Gajjar A, Savjani J. Drug solubility: importance and enhancement techniques. International Scholarly Research Network ISRN Pharmaceutics; 2012. p. 1-10.
8. Dey S, Patro S, Babu N, Murthy P, Panda S. Development and validation of a stability indicating RP-HPLC method for estimation of atazanavir sulphate in bulk. J Pharm Anal 2013;76:177-86.

9. Bhirud S, Hiremath S. Stability indicating RP-HPLC method for the determination of atazanavir sulphate in bulk and dosage form. Drug Invention Today 2013;5:81-6.

10. Seshachalam U, Rao N, Haribabu B, Chandrashekhar B. Determination of atazanavir in the presence of its degradation products by a stability indicating LC method. Chromatographia 2007;65:355-8.

11. Cattaneo D, Maggioalo M, Ripamonti D, Perico P. Determination of atazanavir in human plasma by HPLC with UV Detection. J Chromatographic Sci 2008;46:485-9.

12. Shrinivasu K, Rao J, Raju N, Mukkanti K. A validated RP-HPLC method for the determination of atazanavir in pharmaceutical dosage form. J Chem 2011;1:453-56.

13. Jain HK, Ranjale R. Development and validation of RP-HPLC method for simultaneous estimation of cefoperazone and tazobactam in marketed formulation. Int J Pharm Pharm Sci 2014;6:462-5.

14. Devkare PN, Jain HK. Development and validation of RP-HPLC method for simultaneous estimation of S(-) amlodipine besylate and clopidogrel bisulphate in tablet dosage form. Int J Pharm Pharm Sci 2013;5:770-5.

15. ICH Harmonized-tripartite guidelines, validation of analytical procedure: text and methodology Q2 (R1); 2005.

16. Sinha S, Ali M, Ali J. Solid dispersion as an approach for bioavailability enhancement of poorly water-soluble drug ritonavir. PharmSciTech 2010;2:518-27.

17. Yadav $P$, Kumar V, Singh U, Bhat $H$, Mazumder B. Physicochemical characterization and in vitro dissolution studies of solid dispersions of ketoprofen with PVP K30 and Dmannitol. Saudi Pharm J 2013;21:77-84.

18. Balata G, Mahdi M, Bakera R. Improvement of solubility and dissolution properties of clotrimazole by solid dispersions and inclusion complexes. Indian J Pharm Sci 2011;5:51726.

19. Hadiabdic J, Elezovic A, Rahic O, Mujezin I. Effect of cyclodextrin complexation on the aqueous solubility of diazepam and nitrazepam: phase-solubility analysis, thermodynamic properties. Am J Anal Chem 2012;3:811-20.

20. Nama M, Gonugunta C, Veerareddy P. Formulation and evaluation of gastroretentive dosage forms of clarithromycin. Pharm SciTech 2008;9:521-35. 
21. Gambhire M, Ambade K, Kurmi K, Kadam V, Jadhav K. Development and in vitro evaluation of an oral floating matrix tablet formulation of diltiazem hydrochloride. PharmSciTech 2007;3:1-9.

22. Shimpi S, Chauhan B, Mahadik K, Paradkar A. Preparation and evaluation of diltiazem hydrochloride-gelucire 43/01 floating granules prepared by melt granulation. PharmSciTech 2004;3:1-6.

23. Patel D, Patel N, Patel V, Bhatt D. Floating granules of ranitidine hydrochloride-gelucire 43/01: formulation optimizat0ion using factorial design. PharmSciTech 2007;2:1-7. 